\title{
Research of ergonomic comprehensive evaluation for suit production operation based on hybrid method with IAHP and gray entropy
}

\author{
Laihong $\mathrm{Du}^{1,2^{*}} \mathbb{D}$, Hua Chen ${ }^{1}$ and Yadong Fang
}

\author{
${ }^{*}$ Correspondence: \\ dlh06@xaufe.edu.cn \\ ${ }^{1}$ School of Mechanical \\ and Electrical Engineer, Xi'an \\ Technological University, \\ Xi'an 710021, China \\ Full list of author information \\ is available at the end of the \\ article
}

\begin{abstract}
To solve the problem of ergonomic evaluation of suit production system, a hybrid method of IAHP and gray entropy theory is proposed. Firstly, literature reviews for ergonomics evaluation tools and techniques are introduced. Furthermore, ergonomic evaluation index system of suit operation is established according to production practice. Besides, a comprehensive evaluation models process of gray entropy and IAHP is introduced. Finally, a detailed evaluation process of suit sewing, ironing and clipping operation is introduced by an example, and the results show that the evaluation method of the paper is helpful to verify the feasibility and effectiveness of the operation system improvement demonstration.
\end{abstract}

Keywords: Rgonomic evaluation, IAHP, Gray entropy, Suit production, Evaluation index system

\section{Introduction}

It has been estimated that more than a quarter of all injuries related to industrial work are directly associated with Manual Materials Handling (MMH) activities [1]. Suit production is a kind of typical industry of intensive labor, complicate procedure, more variety and minor batch. Unreasonable procession and operation method are recognized as a major cause of injury in general and an important contributor to the etiology of low back pain (LBP) in particular [2]. Ergonomics, as an interdiscipline, researches system relationship of human, machine and environment, which achieve the goal of optimizing man-machine performance by identifying and reducing the risk factors in the work at the early stage[3]. There are observation method, experimental method and computer simulation method in ergonomics study. The observation method mainly analyzes ergonomics problem by means of questionnaire and video tracking in statistics, and its main disadvantages are long period, difficult to quantify and poor adaptability. The experimental method is mainly used surface electromyography (sEMG) to test and evaluate the labor load by applying electrode slices or wearable devices to the lumbar spine of the back. Although the method can accurately obtain the force or torque of human muscles and bones, its procedure is tedious, which causes discomfort of worker

(c) The Author(s), 2021. Open Access This article is licensed under a Creative Commons Attribution 4.0 International License, which permits use, sharing, adaptation, distribution and reproduction in any medium or format, as long as you give appropriate credit to the original author(s) and the source, provide a link to the Creative Commons licence, and indicate if changes were made. The images or other third party material in this article are included in the article's Creative Commons licence, unless indicated otherwise in a credit line to the material. If material is not included in the article's Creative Commons licence and your intended use is not permitted by statutory regulation or exceeds the permitted use, you will need to obtain permission directly from the copyright holder. To view a copy of this licence, visit http:// creativecommons.org/licenses/by/4.0/. 
Table 1 Comparative analysis of comprehensive evaluation method

\begin{tabular}{lll}
\hline Method & Description of method & Feature analysis \\
\hline Topsis & $\begin{array}{l}\text { Relative approach degree of the ideal solution is } \\
\text { utilized as evaluation criteria }\end{array}$ & $\begin{array}{l}\text { It is not easy to solve ideal solution, and the } \\
\text { method subjectivity is strong }\end{array}$ \\
AHP & $\begin{array}{l}\text { Multi-criteria decision-making is realized based } \\
\text { on qualitative and quantitative analysis by deter- } \\
\text { mining scale of indexes importance }\end{array}$ & $\begin{array}{l}\text { Point judgment matrix may be incaccurate due to } \\
\text { decider grasp incomplete information }\end{array}$ \\
FCAM & $\begin{array}{l}\text { Each evaluation index is evaluated and } \\
\text { sequenced on the basis of fuzzy mathematics } \\
\text { and maximum membership degree principle }\end{array}$ & $\begin{array}{l}\text { Matrix is decided by membership degree. it is } \\
\text { difficult to determine the membership function } \\
\text { reasonably and effectively }\end{array}$ \\
GCA & $\begin{array}{l}\text { It is a multiple statistical method, and describes } \\
\text { relationship of evaluation indicators by correla- } \\
\text { tion analysis }\end{array}$ & $\begin{array}{l}\text { The method has features of clear concept, simple } \\
\text { calculation. However, it has certain subjectivity } \\
\text { due to equal rights treatment }\end{array}$ \\
EM & $\begin{array}{l}\text { Entropy weight of index is determined by infor- } \\
\text { mation entropy }\end{array}$ & $\begin{array}{l}\text { The method is not suitable for subjective evalu- } \\
\text { ation }\end{array}$ \\
\hline
\end{tabular}

body [4]. Computer simulation method realizes rapid, accurate and low-cost ergonomics evaluation in virtual environment by computer aid tools integrated digital human models(DHM), and it can be tested repeatedly [5].

\subsection{Related work}

Presently, many commercial tools are applied in a proactive evaluation of ergonomics issues, such as Dassault Systèmes' SAFEWORK, Siemens's JACK and NEXGEN's HumanCAD. Throughout the globe, diverse industrial sectors are harnessing benefits of DHMS software applications. Some of them include automobile, aviation and aerospace, defense research, health care, general industrial applications, clothing and textile, service and animation, agricultural division, product design and so forth [6]. Patel Thaneswer constructs customizable DHM in DELMIA software and finishes virtual simulation and evaluation of thresher product [7]. Yin $\mathrm{H}$ utilizes JACK software to construct DHM and evaluate body accessibility, visibility and comfortable [8]. Jie Zhang takes the manmachine efficiency requirements of accessibility and comfort into account to propose an evaluation method for the layout of the cockpit manipulating equipment in the virtual reality environment [9]. Mengni Li establishes the elderly digital human model corresponding to existing rehabilitation products with the Jack software and obtains the ergonomic design data of the lower limb rehabilitation behavior of the elderly through the ergonomic simulation evaluation [10].

Suit production belongs to labor-intensive industries, and work-related musculoskeletal disorders occur frequently in suit production lines. However, there are limited researches on man-machine ergonomics of the garment production system, especially the multi-objective ergonomics evaluation and improvement. In the present evaluation method, there are widely used methods, such as a technique for order preference by similarity to ideal solution (Topsis) [11], AHP [12], fuzzy comprehensive assessment method (FCAM) [13], gray correlation analysis(GCA) [14], entropy method (EM) [15] and so forth. Method's features are introduced in Table 1. Topsis method is not easy to solve the ideal solution, and the method subjectivity is strong. AHP depends on the point judgment matrix, and it may be inaccurate due to the decider grasp incomplete information. FCAM method is difficult to determine the membership function reasonably 


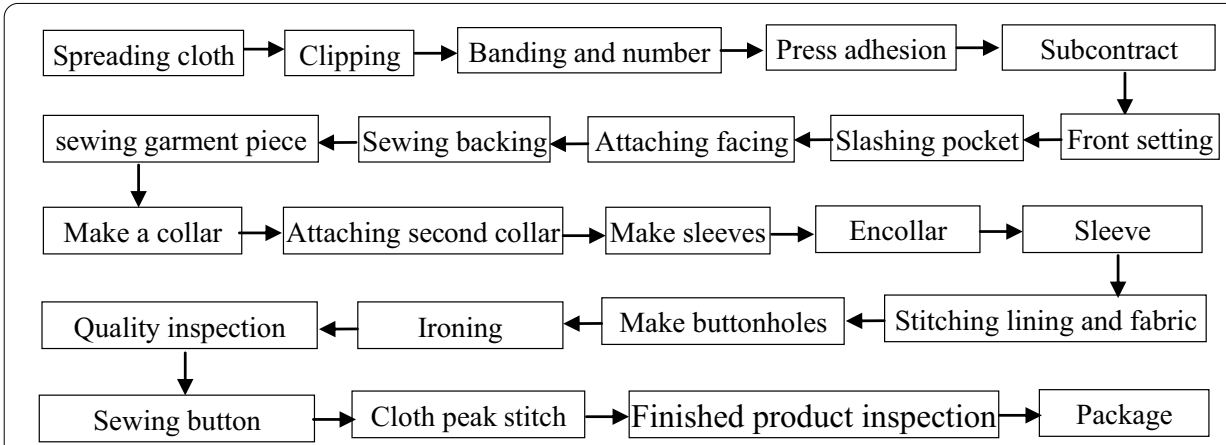

Fig. 1 Production process of suit

Table 2 Working time information

\begin{tabular}{lll}
\hline Project & Time & Total \\
\hline Working time & $8: 00-12: 20 / 13: 10-19: 20$ & $630 \mathrm{~min} /$ day \\
Dining time & $12: 20-13: 10$ & $50 \mathrm{~min}$ \\
Shift & 1 & $1 \mathrm{shift} /$ day \\
Working day & 26 & 26 day/month \\
\hline
\end{tabular}

and effectively. GCA method has certain subjectivity due to equal rights treatment. EM method depends on information entropy, and it is not suitable for subjective evaluation. The ergonomics evaluation index system belongs to a hierarchy decision structure, and indexes information is fuzzy, uncertain and incomplete. Interval analytic hierarchy process (IAHP) is an improvement and extension approach for AHP, and point judgment matrix is replaced by an interval judgment matrix in the method to resolve inaccurate decision problem. Thus, evaluation index subjective weight is determined determination by IAHP method. Entropy method is an objective weighting way, and objective index weight can be calculated by information entropy. Besides, gray correlation analysis has obvious advantages in the theoretical analysis of small sample systems with inaccurate and incomplete information. This method offers another novelty for the present study which was not observed in the literature review especially in the ergonomics evaluation field. According to the above analysis, the paper applies the gray correlation analysis method to solve problems of ergonomics assessment for three typical suit operations, and index weights are determined in terms of interval analytic hierarchy process (IAHP) and entropy method.

\subsection{Fatigue analysis of suit production operations}

The production process of suits mainly includes discharge, blank clipping, piece bonding, sewing, ironing, finishing, packaging, and storage. The flowchart is indicated by Fig. 1, and its working survey result is shown in the following Table 2. Sewing workers maintain the sitting forward-leaning posture for a long time as shown in Fig. 2, and it may cause hypopsia and lumbar damage for long hours of focusing on one place and repeated sideways or bending. Ironing workers hold tools for a long time as shown in Fig. 3, which often leads to right limb pain. Clipping workers stand for a long time, and 


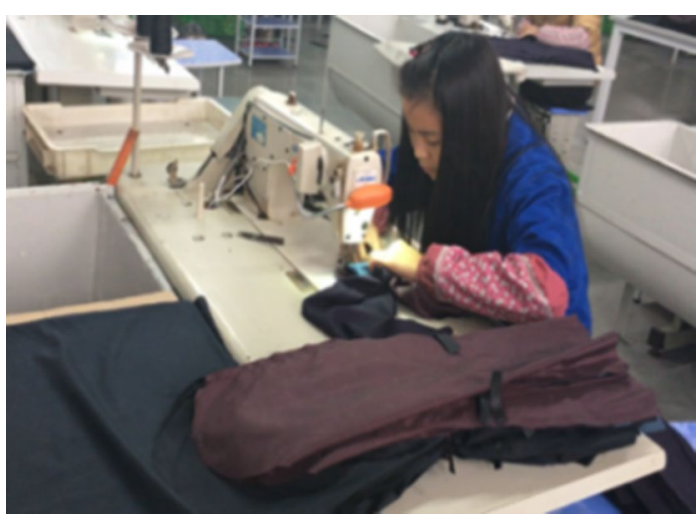

Fig. 2 Sewing operation

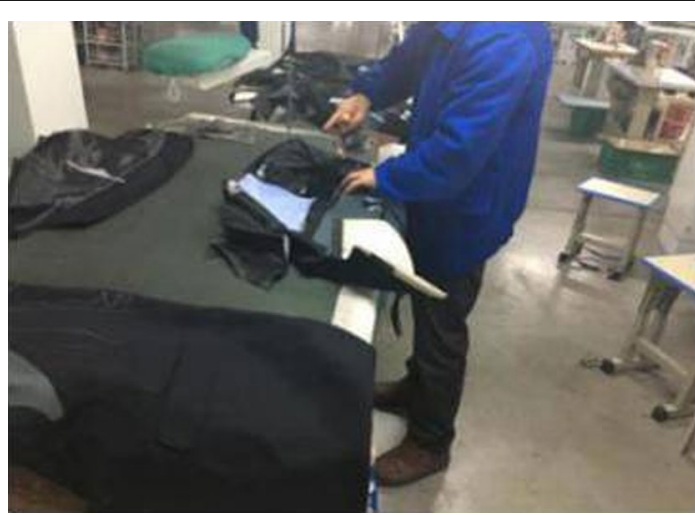

Fig. 3 Ironing operation

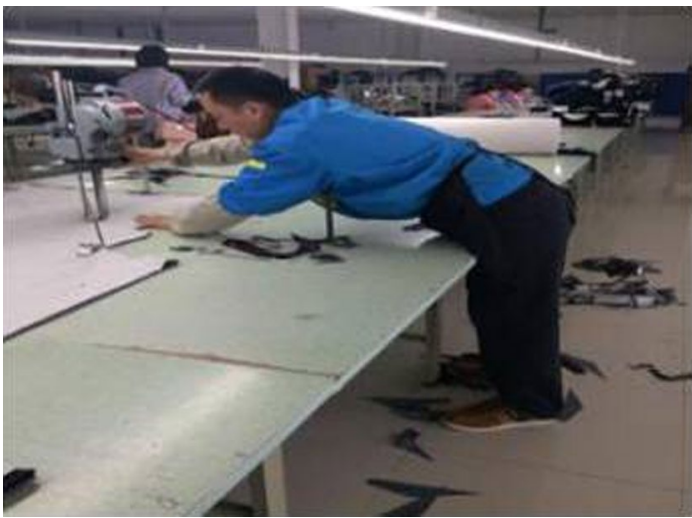

Fig. 4 Clipping operation

the movement range in the operation process is larger, as shown in Fig. 4. Besides, cloth strip placement in the process is unreasonable, and most operations are complicated, which led to physical fatigue for workers. 


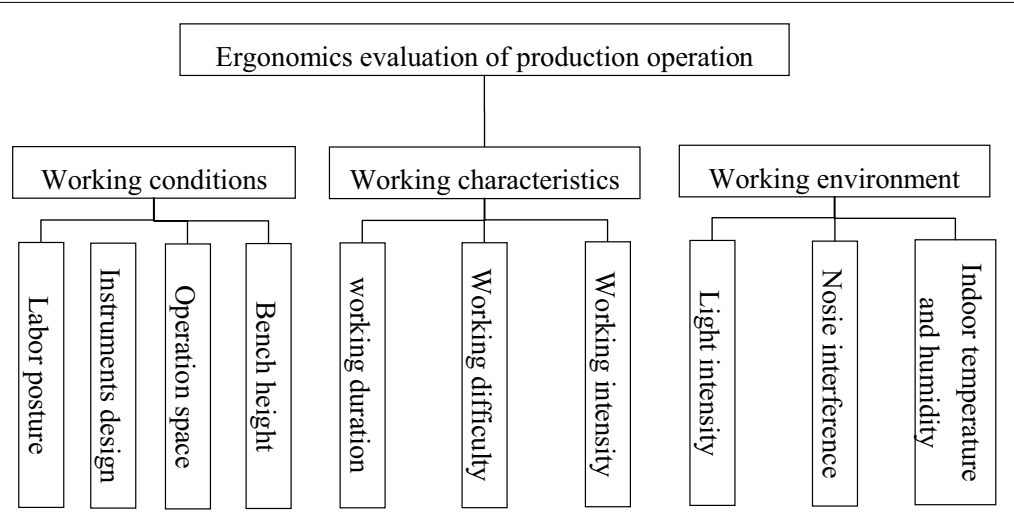

Fig. 5 Construction of ergonomic evaluation system

\section{Methods}

\subsection{Ergonomics evaluation models}

Ergonomics evaluation models can be analyzed by 4M1E method (Man, machine, material, method and environment). Operator status includes physical condition, work proficiency and so on. Machine factor consists of machine layout, matching of workers and equipment, machine reliability, etc. The material factor is the feature of cloth strip, such as volume, weight and mechanical property. Method factor is the process of production and operation, such as working duration, working difficulty and working intensity. Environment factor is made up of light intensity, noise interference, indoor temperature and humidity, dust sources and so on. Applying the principles of ergonomics, management and statistics, the evaluation index system is constructed from three aspects of working conditions, working characteristics and working environment, as shown in Fig. 5. Considering the relationship of man, machine and enviroment, ergonomics evaluation models emphasize matching of workers and equipment (working condition), material factor (working characteristics) and working environment by applying the principles of ergonomics, management and statistics. Matching of workers and equipment is the spatial location area of workermachine interaction, the higher the matching degree of man and machine, the better the ergonomics coordination.

\section{(1) Working conditions $\left(U_{1}\right)$}

When operating objects, tools, and facility layout are unreasonable, the operation space may be unreachable, and operators are required to finish the work with improper postures such as body excessive forward extension, twisting and bending. The increase in workload easily causes work fatigue. Therefore, labor posture $\left(U_{11}\right)$, instruments design $\left(U_{12}\right)$, operation space $\left(U_{13}\right)$ and bench height $\left(U_{14}\right)$ are the main assessment factors.

\section{(2) Working characteristics $\left(U_{2}\right)$}

Suit production belongs to labor-intensive enterprises, and their working characteristics directly affect the fatigue of assembly line workers. The greater the labor intensity 
Table 3 Grade division of duration and labor intensity index

\begin{tabular}{llllll}
\hline Evaluation level & Very poor & Poor & Fair & Good & Excellent \\
\hline Duration $\left(U_{21}\right)$ & {$[360,300)$} & {$[120,300)$} & {$[60,120)$} & {$[30,60)$} & {$[0,30)$} \\
Labor intensity index $\left(U_{22}\right)$ & {$[25,30)$} & {$[20,25)$} & {$[15,20)$} & {$[10,15)$} & {$[0,10)$} \\
\hline
\end{tabular}

and the longer the duration, the easier the employees are fatigued. Thus working duration $\left(U_{21}\right)$, working difficulty $\left(U_{22}\right)$ and working intensity $\left(U_{23}\right)$ are regarded as key factors. According to the China Classification of Manual Labor Intensity (GB3869-1997) and operation time determination criteria, its grade division is shown in Table 3. The physical labor intensity is calculated according to Eq. (1). Here, $I$ is physical labor intensity index, $T$ is the labor time rate, $M$ is the average capacity metabolism rate for $8 \mathrm{~h}$ of workdays, $S$ is the gender coefficient, and $W$ is the coefficient of physical labor mode.

$$
I=T \cdot M \cdot S \cdot W \cdot 10
$$

(3) Working environment $\left(U_{3}\right)$

A poor working environment may lead to worker fatigue. For example, it will cause visual fatigue for the worker by too strong or weak light, and appropriate temperature and humidity will also cause operator fatigue. The working environment includes light intensity $\left(U_{31}\right)$, noise interference $\left(U_{32}\right)$, and indoor temperature and humidity $\left(U_{33}\right)$.

\subsection{Algorithmic framework}

The algorithmic framework is presented in this section. The framework subsumes the objective weight determination method with entropy theory, the subjective weight determination method of IAHP and comprehensive evaluation based on gray correlation theory.

Algorithm 1 Evaluation index objective weight determination method with entropy theory.

\section{(1) Data standardization processing}

The evaluation matrix $X$ is composed of $m$ evaluation criteria and $n$ evaluation indexes, and it is $X=\left(x_{\mathrm{ij}}\right)_{\mathrm{m} \times \mathrm{n}}, i=1,2, \ldots, m, j=1,2, \ldots, n$. In order to eliminate the influence of different dimensions on the evaluation results, the indexes need to be standardized:

$$
\begin{aligned}
& \text { Positive indexes } \quad x_{i j}^{\prime}=\frac{x_{i j}-\min x_{n j}}{\max x_{n j}-\min x_{n j}} \\
& \text { Negative indexes } \quad x_{i j}^{\prime}=\frac{\max x_{n j}-x_{i j}}{\max x_{n j}-\min x_{n j}}
\end{aligned}
$$

The proportion of the value of the $i$ th individual in the index $j$ is $y_{\mathrm{ij}}$ : 


$$
y_{i j}=x_{i j}^{\prime} / \sum_{i=1}^{m} x_{i j}^{\prime}
$$

(2) Calculation of index entropy value and variation coefficient

The entropy value of $j$ th index is $e_{j}$ :

$$
e_{j}=-k \sum_{i=1}^{m} y_{i j} \ln y_{i j}
$$

where $k=1 / \ln m$. If $y_{1}=y_{2}=\ldots y_{\mathrm{n}}$, the entropy can be got the extremum $e_{j m a x}=\ln \mathrm{m}$ by Lagrangian method.

Coefficient of variation $d_{j}$ is:

$$
d_{j}=1-e_{j}
$$

(3) Calculation of the weight of evaluation index

The weight of the $j$ th index is $W_{j}^{\text {entropy }}$

$$
W_{j}^{\text {entropy }}=d_{j} / \sum_{i}^{m} d_{j}
$$

(4) Determination of the sample evaluation value $S_{i}$

$$
S_{i}=\sum_{i=1}^{m} W_{j}^{\text {entropy }} y_{i j}
$$

Algorithm 2 Evaluation index subjective weight determination method with IAHP.

\section{(1) Interval judgment construction}

According to $1 \sim 9$ scale method, interval number judgment matrix $R$ is constructed, and $r_{\mathrm{ij}}$ is the interval number of interval number judgment matrix $R$ in row $i$ and col-

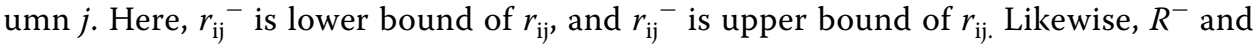
$R^{+}$are, respectively, lower bound and upper bound of $R$.

$$
R=\left(r_{i j}^{-}, r_{i j}^{+}\right)_{n \times n}=\left[R^{-}, R^{+}\right]
$$

\section{(2) Parameters calculation and consistency check}

The parameters $\mathrm{k}$ and $\mathrm{m}$ are calculated, and consistency test of the interval judgment matrix is conducted. When $k \leq 1$ and $m \geq 1$, the judgment matrix has good consistency. When $k>1$ or $m<1$, it indicates that the inconsistency degree of the 
judgment matrix exceeds the allowable range, and the interval judgment matrix is rebuilt until it passes the consistency test.

$$
\begin{aligned}
& k=\sum_{j=1}^{n} \frac{1}{\sum_{i=1}^{n} r_{i j}^{+}} \\
& m=\sum_{j=1}^{n} \frac{1}{\sum_{i=1}^{n} r_{i j}^{-}}
\end{aligned}
$$

(3) Determine the weight of the interval judgment matrix

$\lambda^{-}$is eigenvector of $R^{-}$, and $\lambda^{+}$is eigenvector of $R^{-}$, and then the interval weight vector $W^{\mathrm{I}}$ is determined by using Eq. (11). Here, $W_{\mathrm{i}}^{\mathrm{I}}=\left[k \lambda_{\mathrm{i}}{ }^{-}, m \lambda_{\mathrm{i}}{ }^{+}\right], i=1,2, \ldots n$.

$$
W^{I}=\left[k \lambda^{-}, m \lambda^{+}\right]=\left(W_{1}^{I}, W_{2}^{I}, \ldots, W_{n}^{I}\right)
$$

\section{(4) Calculation of the probability degree $P$}

In order to compare each index importance, the weight interval is transformed into a point value by sorting the probability degree $P$, and the probability degree $P$ can be calculated by Eq. (12). Here, $L\left(W_{\mathrm{i}}^{\mathrm{I}}\right)$ and $L\left(W_{\mathrm{j}}^{\mathrm{I}}\right)$ are, respectively, ith and jth element length of interval weight vector $W^{\mathrm{I}}$, and $L\left(W_{\mathrm{i}}^{\mathrm{I}}\right)=W_{\mathrm{i}}^{\mathrm{I}+}-W_{\mathrm{i}}^{\mathrm{I}-}, L\left(W_{\mathrm{j}}^{\mathrm{I}}\right)=W_{\mathrm{j}}^{\mathrm{I}+}-W_{\mathrm{j}}^{\mathrm{I}-}$.

$$
P\left(W_{i}^{I}>W_{j}^{I}\right)=\max \left(0,1-\frac{\max \left(0, W_{j}^{I+}-W_{i}^{I-}\right)}{L\left(W_{i}^{I}\right)+L\left(W_{j}^{I}\right)}\right)
$$

\section{(5) Construction of probability judgment matrix $W^{\mathrm{IAHP}}$}

The interval weight vector $W^{d}$ and the probability judgment matrix among the interval numbers $P=\left[P_{\mathrm{ij}}\right]_{n \times n}$ are constructed. via Eq. (13), the possible degree point value matrix is transformed into each index weight, and then, the weight vector $W^{I A H P}$ is formed. Here, $W^{\mathrm{IAHP}}=\left(W_{1}^{\mathrm{IAHP}}, W_{2}^{\mathrm{IAHP}}, \ldots, W_{\mathrm{n}}^{\mathrm{IAHP}}\right)$.

$$
W_{i}^{I A H P}=\frac{\sum_{j=1}^{n} P_{i j}+0.5 n-1}{n(n+1)}
$$

The comprehensive weight of evaluation index $W_{i}$ is determined according to Eq. (14).

$$
W_{i}=\frac{W_{i}^{I A H P} W_{i}^{\text {entropy }}}{\sum_{i=1}^{n} W_{i}^{I A H P} W_{i}^{\text {entropy }}}
$$


Algorithm 3 Comprehensive evaluation of ergonomics based on gray correlation theory.

(1) Determination of the optimal index set $X^{*}$

$$
X^{*}=\left\{x_{i}^{*} \mid x_{i}^{*}=\max x_{i j} \text { or } \min x_{i j}\right\}
$$

where $i=1,2, \ldots, m ; j=1,2, \ldots, n ; \max x_{\mathrm{ij}}$ and $\min x_{\mathrm{ij}}$ are, respectively, the most and least satisfied value in different evaluation criteria of the same index. $x_{i}^{*}$ is optimal value of index to be evaluated.

(2) Calculation of the difference matrix

$$
D=\left\{d_{i j}\left|d_{i j}=\right| x_{i j}-x_{i}^{*} \mid\right\}
$$

where $x_{\mathrm{ij}}$ is original value, $x_{\mathrm{i}}{ }^{*}$ is optimal value, and $d_{\mathrm{ij}}$ is difference of original and optimal value.

(3) Calculation of gray correlation coefficient and weighted degree

The correlation coefficient of $X_{\mathrm{i}}$ to $X_{0}$ of the $K$ th index is:

$$
\xi_{\mathrm{i}}(k)=\frac{\Delta_{\min }+\alpha \Delta_{\max }}{\Delta_{i}(k)+\alpha \Delta_{\max }}=\frac{\min _{i} \min _{k}\left|x_{0 k}-x_{i k}\right|+\alpha \max _{i} \max _{k}\left|x_{0 k}-x_{i k}\right|}{\left|x_{0 k}-x_{i k}\right|+\alpha \max _{i} \max _{k}\left|x_{0 k}-x_{i k}\right|}
$$

where $x_{0 \mathrm{k}}$ is $k$ th element of optimal index set $X^{*}$, and $x_{\mathrm{ik}}$ is $k$ th element of the original index set $X \nabla_{\min }$ is the minimum difference of $k$ th element value between optimal index set $X^{*}$ and the original index set $X$, and $\nabla_{\max }$ is the maximum difference. $\nabla_{\min } \leq \nabla_{i}(\mathrm{k})$, and range of correlation coefficient is $\xi_{i}(k) \in(0,1]$. Resolution coefficient $\alpha$ is a parameter associated with $\nabla_{\max }$ to control $\xi_{i}(k)$. In terms of literature [16] conclusions, the value of $\alpha$ is more higher, and the value of $\xi_{i}(k)$ is higher in the interval $(0,0.5]$, which effects on correlation coefficient is more significant. Quite the reverse, the value of $\alpha$ is higher, and the value of $\xi i(k)$ is lower in the interval $(0.5,1]$. Thus, the resolution coefficient $\alpha=0.5$.

The gray correlation weighted degree is:

$$
r_{i}=W(k) \sum \xi_{i}(k)
$$

where $W(k)$ is the weight of the $k$ th index.

(4) Determination of multi-level gray correlation

$$
L^{i+1}=W^{i} \cdot L^{i}
$$

where $W^{i}$ is current level evaluation factor weights, $L^{i}$ is the previous evaluation results.

\section{Results and discussion}

\subsection{Experimental preparation}

The research object is a suit production operation, and it is evaluated according to the assessment system shown in Fig. 2. The evaluation results are divided into five grades: 
Table 4 Evaluation result of sewing operation

\begin{tabular}{lllllllllll}
\hline & $U_{\mathbf{1 1}}$ & $U_{\mathbf{1 2}}$ & $U_{\mathbf{1 3}}$ & $U_{\mathbf{1 4}}$ & $U_{\mathbf{2 1}}$ & $U_{\mathbf{2 2}}$ & $U_{\mathbf{2 3}}$ & $U_{\mathbf{3 1}}$ & $U_{\mathbf{3 2}}$ & $U_{\mathbf{3 3}}$ \\
\hline$v_{1}$ & 0.15 & 0.25 & 0.2 & 0.15 & 0 & 0 & 0 & 0.2 & 0.25 & 0.3 \\
$v_{2}$ & 0.85 & 0.65 & 0.75 & 0.7 & 1 & 0 & 0.2 & 0.2 & 0.3 & 0.1 \\
$v_{3}$ & 0 & 0 & 0.05 & 0.1 & 0 & 0 & 0.2 & 0.4 & 0.05 & 0.25 \\
$v_{4}$ & 0 & 0.1 & 0 & 0 & 0 & 1 & 0.35 & 0.15 & 0.15 & 0.2 \\
$v_{5}$ & 0 & 0 & 0 & 0.05 & 0 & 0 & 0.25 & 0.05 & 0.25 & 0.15 \\
\hline
\end{tabular}

very poor $\left(v_{1}\right)$, poor $\left(v_{2}\right)$, fair $\left(v_{3}\right)$, good $\left(v_{4}\right)$ or excellent $\left(v_{5}\right)$, and the comment set is $V=\{v 1, v 2, v 3, v 4, v 5\}$. According to the survey production data of Chian WZ Group Co., Ltd. in 2020, the daily average output of WZ garment factory is about 500 pieces, the working time of workers is 630 min (AM 8:00-12:20/PM 13:10-19:20) per day, and duration time is $120-150 \mathrm{~min}$. Furthermore, the lunchtime of workers is $50 \mathrm{~min}$ (PM 12:20-13:10), Labor time $T_{\text {Sewing }}=T_{\text {Ironing }}=T_{\text {Clipping }}=$ Net working time in workday/ Total length of the workday $=541 / 630=85.9 \%$

Labor intensity index is acquired by Eq. (1) and China manual labor intensity classification criterion (GB3869-1997).

$$
\begin{aligned}
& I_{\text {Sewing }}=T_{\text {Sewing }} \cdot M_{\text {Sewing }} \cdot S_{\text {Sewing }} \cdot W_{\text {Sewing }} \cdot 10=0.859 \times 1.936 \times 1.3 \times 0.05 \times 10=1.08 \\
& I_{\text {Ironing }}=T_{\text {Ironing }} \cdot M_{\text {Ironing }} \cdot S_{\text {Ironing }} \cdot W_{\text {Ironing. }} \cdot 10=0.859 \times 3.158 \times 1 \times 0.05 \times 10=1.36 \\
& I_{\text {Clipping }}=T_{\text {Clipping }} \cdot M_{\text {Clipping }} \cdot S_{\text {Clipping }} \cdot W_{\text {Clipping }} \cdot 10=0.859 \times 3.619 \times 1 \times 0.05 \times 10=1.55
\end{aligned}
$$

For sewing, ironing and clipping operations, quantitative index evaluation result is determined by its interval division, and the qualitative index is evaluated by a questionnaire survey. Twenty industrial engineering experts are invited to evaluated qualitative index $\left(U_{11}, U_{12}, U_{13}, U_{14}, U_{23}, U_{31}, U_{32}\right.$ and $\left.U_{33}\right)$ according to the assigned evaluation standards and then calculate the frequency $\mu$ of each evaluation index $U$ to evaluation grade $V$ in terms of Eq. (20). The assessment results in detail are shown in Tables 4, 5 and 6.

Table 5 Evaluation result of ironing operation

\begin{tabular}{lllllllllll}
\hline & $U_{\mathbf{1 1}}$ & $U_{\mathbf{1 2}}$ & $U_{\mathbf{1 3}}$ & $U_{\mathbf{1 4}}$ & $U_{\mathbf{2 1}}$ & $U_{\mathbf{2 2}}$ & $U_{\mathbf{2 3}}$ & $U_{\mathbf{3 1}}$ & $U_{\mathbf{3 2}}$ & $U_{\mathbf{3 3}}$ \\
\hline$v_{1}$ & 0.5 & 0.7 & 0.75 & 0 & 0 & 0 & 0 & 0 & 0 & 0 \\
$v_{2}$ & 0.15 & 0.2 & 0.15 & 0 & 1 & 0 & 0 & 0.1 & 0.1 & 0.2 \\
$v_{3}$ & 0.2 & 0.1 & 0.1 & 0.4 & 0 & 0 & 0.7 & 0.2 & 0.2 & 0.5 \\
$v_{4}$ & 0.15 & 0 & 0 & 0.4 & 0 & 1 & 0.3 & 0.4 & 0.55 & 0.15 \\
$v_{5}$ & 0 & 0 & 0 & 0.2 & 0 & 0 & 0 & 0.3 & 0.15 & 0.15 \\
\hline
\end{tabular}

Table 6 Evaluation result of clipping operation

\begin{tabular}{lllllllllll}
\hline & $U_{\mathbf{1 1}}$ & $U_{\mathbf{1 2}}$ & $U_{\mathbf{1 3}}$ & $U_{\mathbf{1 4}}$ & $U_{\mathbf{2 1}}$ & $U_{\mathbf{2 2}}$ & $U_{\mathbf{2 3}}$ & $U_{\mathbf{3 1}}$ & $U_{\mathbf{3 2}}$ & $U_{\mathbf{3 3}}$ \\
\hline$v_{1}$ & 0.5 & 0.7 & 0.75 & 0 & 0 & 0 & 0 & 0 & 0 & 0 \\
$v_{2}$ & 0.15 & 0.2 & 0.15 & 0 & 1 & 0 & 0 & 0.1 & 0.1 & 0.2 \\
$v_{3}$ & 0.2 & 0.1 & 0.1 & 0.4 & 0 & 0 & 0.7 & 0.2 & 0.2 & 0.5 \\
$v_{4}$ & 0.15 & 0 & 0 & 0.4 & 0 & 1 & 0.3 & 0.4 & 0.55 & 0.15 \\
$v_{5}$ & 0 & 0 & 0 & 0.2 & 0 & 0 & 0 & 0.3 & 0.15 & 0.15 \\
\hline
\end{tabular}




$$
\mu_{v_{j}}\left(U_{i}\right)=m_{i j} / \sum_{j=1}^{20} m_{i j}
$$

\subsection{Experimental results and analysis}

Optimal index sets of sewing, ironing and clipping operation are calculated by Eq. (15).

$$
\begin{aligned}
& X_{s}^{*}=\left\{x_{11}, x_{12}, x_{13}, x_{14}, x_{21}, x_{22}, x_{23}, x_{31}, x_{32}, x_{33}\right\}=\{0.85,0.65,0.75,0.7,1,1,0.35,0.4,0.3,0.3\} . \\
& X_{i}^{*}=\left\{x_{11}, x_{12}, x_{13}, x_{14}, x_{21}, x_{22}, x_{23}, x_{31}, x_{32}, x_{33}\right\}=\{0.5,0.7,0.75,0.4,1,1,0.7,0.4,0.55,0.5\} . \\
& X_{c}^{*}=\left\{x_{11}, x_{12}, x_{13}, x_{14}, x_{21}, x_{22}, x_{23}, x_{31}, x_{32}, x_{33}\right\}=\{0.4,0.5,0.7,0.8,1,1,0.7,0.6,0.4,0.5\} .
\end{aligned}
$$

The difference matrix of sewing, ironing and clipping operation can be obtained by Eq. (16)

$$
\begin{aligned}
D_{s} & =\left[\begin{array}{llllllllll}
0.7 & 0.4 & 0.55 & 0.55 & 1 & 1 & 0.35 & 0.2 & 0.05 & 0 \\
0 & 0 & 0 & 0 & 0 & 1 & 0.15 & 0.2 & 0 & 0.2 \\
0.85 & 0.65 & 0.7 & 0.6 & 1 & 1 & 0.15 & 0 & 0.25 & 0.05 \\
0.85 & 0.55 & 0.75 & 0.7 & 1 & 0 & 0 & 0.25 & 0.15 & 0.1 \\
0.85 & 0.65 & 0.75 & 0.65 & 1 & 1 & 0.1 & 0.35 & 0.05 & 0.15
\end{array}\right] \\
D_{i} & =\left[\begin{array}{llllllllll}
0 & 0 & 0 & 0.4 & 1 & 1 & 0.7 & 0.4 & 0.55 & 0.5 \\
0.35 & 0.5 & 0.6 & 0.4 & 0 & 1 & 0.7 & 0.3 & 0.45 & 0.3 \\
0.3 & 0.6 & 0.65 & 0 & 1 & 1 & 0 & 0.2 & 0.35 & 0 \\
0.35 & 0.7 & 0.75 & 0 & 1 & 0 & 0.4 & 0 & 0 & 0.35 \\
0.5 & 0.7 & 0.75 & 0.2 & 1 & 1 & 0.7 & 0.1 & 0.4 & 0.35
\end{array}\right] \\
D_{c} & =\left[\begin{array}{lllllllllll}
0 & 0.2 & 0 & 0.8 & 1 & 1 & 0.7 & 0.6 & 0.4 & 0.5 \\
0.1 & 0 & 0.5 & 0.8 & 0 & 1 & 0.7 & 0.45 & 0.05 & 0.3 \\
0.3 & 0.4 & 0.6 & 0.65 & 1 & 1 & 0 & 0 & 0 & 0 \\
0.3 & 0.5 & 0.7 & 0 & 1 & 0 & 0.4 & 0.45 & 0.15 & 0.35 \\
0.3 & 0.5 & 0.7 & 0.75 & 1 & 1 & 0.7 & 0.5 & 0.4 & 0.35
\end{array}\right]
\end{aligned}
$$

The gray correlation coefficient matrix of sewing, ironing and clipping operation can be determined by Eq. (17).

$$
\begin{gathered}
\xi_{s}=\left[\begin{array}{llllllllll}
0.42 & 0.56 & 0.48 & 0.48 & 0.33 & 0.33 & 0.59 & 0.71 & 0.91 & 1.00 \\
1.00 & 1.00 & 1.00 & 1.00 & 1.00 & 0.33 & 0.77 & 0.71 & 1.00 & 0.71 \\
0.37 & 0.43 & 0.42 & 0.45 & 0.33 & 0.33 & 0.77 & 1.00 & 0.67 & 0.91 \\
0.37 & 0.48 & 0.40 & 0.42 & 0.33 & 1.00 & 1.00 & 0.67 & 0.77 & 0.83 \\
0.37 & 0.43 & 0.40 & 0.43 & 0.33 & 0.33 & 0.83 & 0.59 & 0.91 & 0.77
\end{array}\right] \\
\xi_{i}=\left[\begin{array}{llllllllll}
1.00 & 1.00 & 1.00 & 0.56 & 0.33 & 0.33 & 0.42 & 0.56 & 0.48 & 0.50 \\
0.59 & 0.50 & 0.45 & 0.56 & 1.00 & 0.33 & 0.42 & 0.63 & 0.53 & 0.63 \\
0.63 & 0.45 & 0.43 & 1.00 & 0.33 & 0.33 & 1.00 & 0.71 & 0.59 & 1.00 \\
0.59 & 0.42 & 0.40 & 1.00 & 0.33 & 1.00 & 0.56 & 1.00 & 1.00 & 0.59 \\
0.50 & 0.42 & 0.40 & 0.71 & 0.33 & 0.33 & 0.42 & 0.83 & 0.56 & 0.59
\end{array}\right] \\
\xi_{c}=\left[\begin{array}{llllllllll}
1.00 & 0.71 & 1.00 & 0.38 & 0.33 & 0.33 & 0.42 & 0.45 & 0.56 & 0.50 \\
0.83 & 1.00 & 0.50 & 0.38 & 1.00 & 0.33 & 0.42 & 0.53 & 0.91 & 0.63 \\
0.63 & 0.56 & 0.45 & 0.43 & 0.33 & 0.33 & 1.00 & 1.00 & 1.00 & 1.00 \\
0.63 & 0.50 & 0.42 & 1.00 & 0.33 & 1.00 & 0.56 & 0.53 & 0.77 & 0.59 \\
0.63 & 0.50 & 0.42 & 0.40 & 0.33 & 0.33 & 0.42 & 0.50 & 0.56 & 0.59
\end{array}\right]
\end{gathered}
$$


The data in Tables 4, 5 and 6 are standardized according to Eqs. (2) and (3), and corresponding entropy value and variation coefficient of second-order index can be acquired by Eqs. (4) and (5).

$$
\begin{aligned}
& e_{s}^{(2)}=\{0.26,0.53,0.43,0.57,0,0,0.84,0.79,0.83,0.8\} \\
& e_{i}^{(2)}=\{0.77,0.5,0.45,0.66,0,0,0.38,0.8,0.72,0.77\} \\
& e_{c}^{(2)}=\{0.42,0.58,0.5,0.38,0,0,0.38,0.69,0.67,0.77\} \\
& d_{s}^{(2)}=\{0.74,0.47,0.57,0.43,1,1,0.16,0.21,0.17,0.2\} \\
& d_{i}^{(2)}=\{0.23,0.5,0.55,0.34,1,1,0.62,0.2,0.28,0.23\} \\
& d_{c}^{(2)}=\{0.58,0.42,0.5,0.62,1,1,0.62,0.31,0.33,0.23\}
\end{aligned}
$$

In terms of formula (5), objective weight vector of second-order index is calculated.

$$
\begin{aligned}
& W_{s}^{(2)}=\{0.33,0.21,0.26,0.20,0.46,0.46,0.07,0.36,0.29,0.35\} \\
& W_{i}^{(2)}=\{0.14,0.31,0.34,0.21,0.38,0.38,0.24,0.29,0.39,0.32\} \\
& W_{c}^{(2)}=\{0.27,0.20,0.24,0.29,0.38,0.38,0.24,0.36,0.38,0.26\}
\end{aligned}
$$

The first-order index is calculated by Eq. (7) and then is disposed with normalization. Furthermore, the corresponding entropy value, variation coefficient and weight vector of first-order index can be obtained by Eqs. (4), (5) and (6).

$$
\begin{aligned}
& e_{s}^{(1)}=\{0.47,0.52,0.96\} \\
& e_{i}^{(1)}=\{0.8,0.64,0.82\} \\
& e_{c}^{(1)}=\{0.83,0.64,0.74\} \\
& d_{s}^{(1)}=\{0.53,0.48,0.04\} \\
& d_{i}^{(1)}=\{0.20,0.36,0.18\} \\
& d_{c}^{(1)}=\{0.17,0.36,0.26\} \\
& W_{s}^{(1)}=\{0.5,0.46,0.04\} \\
& W_{i}^{(1)}=\{0.27,0.48,0.24\} \\
& W_{c}^{(1)}=\{0.22,0.46,0.32\}
\end{aligned}
$$

The priority order of evaluation index at all levels is determined by the questionnaire survey: $U_{21}>U_{11}>U_{14}>U_{23}>U_{12}>U_{22}>U_{13}>U_{31}>U_{33}>U_{32} ; U_{11}>U_{14}>U_{12}>U_{13}$; $U_{21}>U_{23}>U_{22}>; U_{31}>U_{33}>U_{32} ; U_{2}>U_{1}>U_{3}$, and interval judgment matrix of each order can be constructed by Eq. (8).

$$
\begin{aligned}
& R_{1}^{(1)}=\left[\begin{array}{l}
1.00,1.00,5.00,7.00,7.00,9.00,3.00,5.00 \\
0.14,0.20,1.00,1.00,3.00,5.00,0.20,0.33 \\
0.11,0.14,0.20,0.33,1.00,1.00,4.00,5.00 \\
0.20,0.33,3.00,5.00,0.20,0.25,1.00,1.00
\end{array}\right] \\
& R_{2}^{(1)}=\left[\begin{array}{l}
1.00,1.00,5.00,7.00,3.00,5.00 \\
0.14,0.20,1.00,1.00,0.25,0.33 \\
0.20,0.33,3.00,4.00,1.00,1.00
\end{array}\right]
\end{aligned}
$$




$$
\begin{aligned}
& R_{3}^{(1)}=\left[\begin{array}{l}
1.00,1.00,5.00,7.00,3.00,5.00 \\
0.14,0.20,1.00,1.00,0.20,0.33 \\
0.20,0.33,3.00,5.00,1.00,1.00
\end{array}\right] \\
& R^{(2)}=\left[\begin{array}{l}
1.00,1.00,0.20,0.33,3.00,5.00 \\
3.00,5.00,1.00,1.00,4.00,5.00 \\
0.20,0.33,0.20,0.25,1.00,1.00
\end{array}\right]
\end{aligned}
$$

Each indexes comprehensive weight can be calculated via Eq. (14).

$$
\begin{aligned}
& W_{1 s}^{(1)}=\{0.50,0.15,0.21,0.13\} \\
& W_{2 s}^{(1)}=\{0.64,0.32,0.04\} \\
& W_{3 s}^{(1)}=\{0.46,0.20,0.35\} \\
& W_{s}^{(1)}=\{0.44,0.54,0.02\} \\
& W_{1 i}^{(1)}=\{0.25,0.26,0.32,0.17\} \\
& W_{2 i}^{(1)}=\{0.57,0.28,0.15\} \\
& W_{3 i}^{(1)}=\{0.38,0.28,0.34\} \\
& W_{i}^{(1)}=\{0.25,0.60,0.15\} \\
& W_{1 c}^{(1)}=\{0.43,0.15,0.20,0.21\} \\
& W_{2 c}^{(1)}=\{0.57,0.28,0.15\} \\
& W_{3 c}^{(1)}=\{0.46,0.27,0.27\} \\
& W_{c}^{(1)}=\{0.21,0.59,0.21\}
\end{aligned}
$$

Multi-order gray relational degree is calculated by Eqs. (18) and (19).

$$
\begin{aligned}
& L_{1 s}^{(1)}=\xi_{1 s} \cdot\left[W_{1 s}^{(1)}\right]^{\mathrm{T}}=\{0.46,1.00,0.40,0.40,0.40\} \\
& L_{2 s}^{(1)}=\xi_{2 s} \cdot\left[W_{2 s}^{(1)}\right]^{\mathrm{T}}=\{0.34,0.78,0.35,0.57,0.35\} \\
& L_{3 s}^{(1)}=\xi_{3 s} \cdot\left[W_{3 s}^{(1)}\right]^{\mathrm{T}}=\{0.85,0.77,0.90,0.74,0.71\} \\
& L_{s}^{(2)}=\left[L_{1 s}^{(1)}, L_{2 s}^{(1)}, L_{3 s}^{(1)}\right] \cdot\left[W_{s}^{(1)}\right]^{\mathrm{T}}=\{0.41,0.88,0.39,0.50,0.38\} \\
& L_{1 i}^{(1)}=\xi_{1 i} \cdot\left[W_{1 i}^{(1)}\right]^{\mathrm{T}}=\{0.93,0.52,0.58,0.55,0.48\} \\
& L_{2 i}^{(1)}=\xi_{2 i} \cdot\left[W_{2 i}^{(1)}\right]^{\mathrm{T}}=\{0.35,0.73,0.43,0.56,0.35\} \\
& L_{3 i}^{(1)}=\xi_{3 i} \cdot\left[W_{3 i}^{(1)}\right]^{\mathrm{T}}=\{0.51,0.60,0.77,0.86,0.67\} \\
& L_{i}^{(2)}=\left[L_{1 i}^{(1)}, L_{2 i}^{(1)}, L_{3 i}^{(1)}\right] \cdot\left[W_{i}^{(1)}\right]^{\mathrm{T}}=\{0.52,0.65,0.52,0.60,0.43\} \\
& L_{1 c}^{(1)}=\xi_{1 c} \cdot\left[W_{1 c}^{(1)}\right]^{\mathrm{T}}=\{0.83,0.70,0.54,0.64,0.52\} \\
& L_{2 c}^{(1)}=\xi_{2 c} \cdot\left[W_{2 c}^{(1)}\right]^{\mathrm{T}}=\{0.35,0.73,0.43,0.56,0.35\} \\
& L_{3 c}^{(1)}=\xi_{3 c} \cdot\left[W_{3 c}^{(1)}\right]^{\mathrm{T}}=\{0.49,0.66,1.00,0.61,0.54\} \\
& L_{c}^{(2)}=\left[L_{1 c}^{(1)}, L_{2 c}^{(1)}, L_{3 c}^{(1)}\right] \cdot\left[W_{c}^{(1)}\right]^{\mathrm{T}}=\{0.48,0.70,0.57,0.58,0.42\}
\end{aligned}
$$

The comparison between three operations evaluations in each of the four methods is plotted in Fig. 6. There is a similarity in the evaluation result of four methods, and the gray correlation degree intervals of the methods are owned by $[0.4 \pm \varepsilon, 0.8 \pm \varepsilon]$, and the upper boundary of IAHP method is relatively smaller. According to the maximum membership 


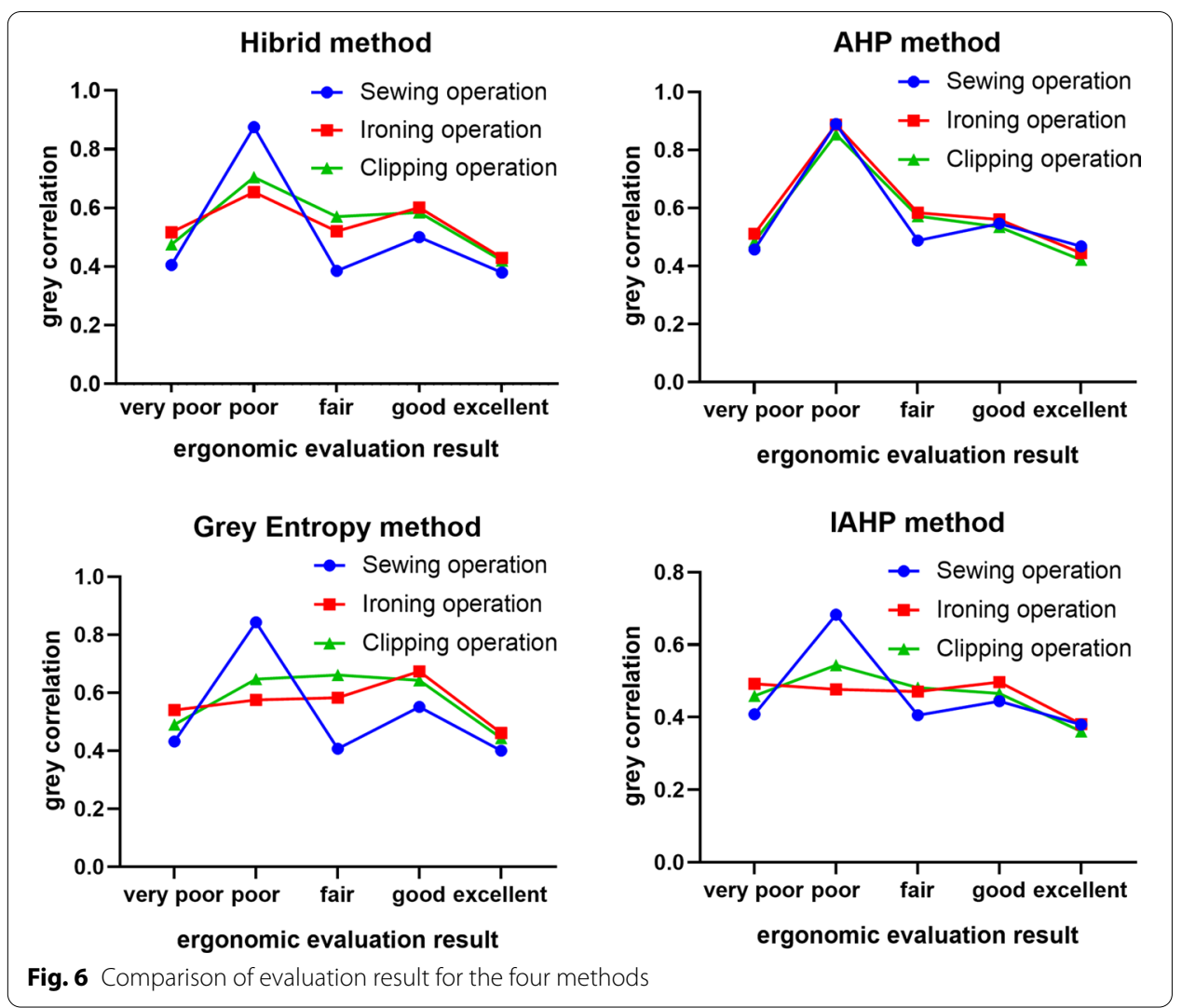

criteria, $L=\max \left(L_{j}^{(2)}(k) \mid j \in\{s, i, c\}, k=1,2, \ldots, 5\right)$. Here, $j=s, k=2$. Thus, it can be seen that the sewing operation ergonomic evaluation result belongs to v2 grade (poor), and it is worst in three production operation ergonomic evaluations. The results in Fig. 6 demonstrate that the hybrid method of IAHP and gray entropy is the most effective, and AHP method is difficult to distinguish the worst operation from sewing, ironing and clipping operation.

Index weight distribution analysis is shown in Fig. 7. Note that, the weight of index $U_{2}$ (working characteristics) in the first level indicators $\left(U_{1}-U_{3}\right)$ is maximum. Besides, the weight of index $U_{21}$ (working duration) and $U_{22}$ (working difficulty) takes a big part of succeeding level indicators $\left(U_{11}-U_{33}\right)$. Therefore, it is important to reduce fatigue and improve work efficiency by improving the working posture of operators.

In terms of the above discussion, sewing operation is the worst one in three production operations ergonomic evaluation. Thus, the contrastive analysis of four ergonomic evaluation results to resolve the sewing operation ergonomic evaluation problem is shown in Fig. 8. Note that, four methods evaluation results aggregated in $v_{2}$ grade, and their gray correlation degrees are roughly 0.8 (the mean of gray correlation degree for four methods is 0.823), except for IAHP method. It is worth emphasizing that the fluctuation value of the hybrid method gray correlation degree means is minimum. Therefore, it can be seen that the hybrid method of IAHP and gray entropy is feasible and reliable to resolve the operation ergonomic evaluation problem. 

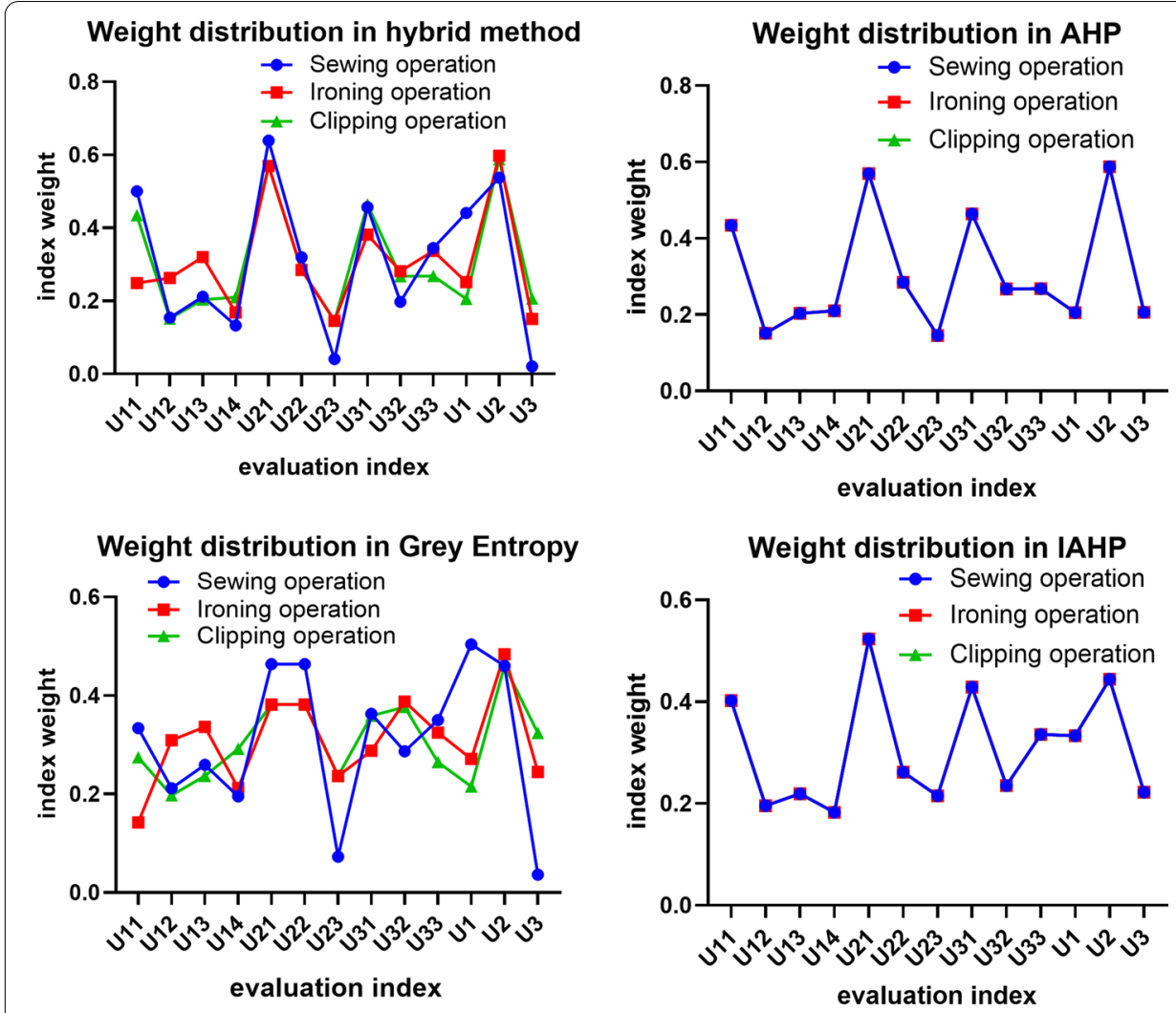

Fig. 7 Analysis of index weight distribution for the four methods

\section{Conclusions and future work}

Most processes of suit production line depend on manual handling, and it is regarded as a major cause of injury and an import contributor to the etiology of LBP in particular for workers. Therefore, it is urgent to solve the above man-machine engineering problem. However, an ergonomic comprehensive evaluation is a prerequisite for human engineering improvement. There are qualitative and quantitative in suit operation ergonomic evaluation factors, and most indexes are fuzzy and gray at the same time.

In the paper, the total ergonomic evaluation index system for suit production operation is constructed from human, machines, tools, workshop layout, operation method and environment. A hybrid method of IAHP and gray entropy theory is firstly applied in typical suit production operation ergonomic evaluation. The results show that the hybrid method of IAHP and gray entropy is the most effective, and it is easy to distinguish the worst operation from the three typical operations. IAHP method replaces the traditional point judgment matrix with interval judgment to resolve incorrect subjective weight decision problems. In the gray entropy method, the entropy weight of the evaluation index is determined by gray information entropy and index basic information, and index weight is improved by entropy weight to calculate the last objective weight. The evaluation method in the paper is helpful to verify the feasibility 


\section{Evaluation method contrastive analysis}

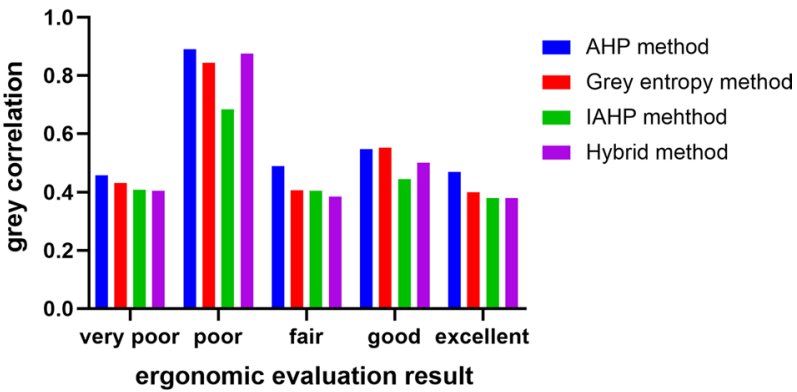

Fig. 8 Contrastive analysis of the four methods evaluation result

and effectiveness of the operation system improvement demonstration. The method presented in this study is general and straightforward to carry out performance optimization of similar systems. The focus of the further research in the paper is to determine the optimum working posture and evaluate productibility of the operation system.

\section{Abbreviations}

IAHP: Interval analytic hierarchy process; MMH: Manual Materials Handling; LBP: Low Back Pain; sEMG: Surface Electromyography; DHM: Digital Human Models; FCAM: Fuzzy Comprehensive Assessment Method; GCA: Gray Correlation Analysis; EM: Entropy Method.

\section{Acknowledgements}

Not applicable.

\section{Authors' contributions}

$L D$, as the primary contributor, completed the analysis, paper writing. $\mathrm{HC}$ and YF participate in experiments that helped to improve typography and English language. All authors read and approved the final manuscript.

\section{Funding}

This research was supported by Scientific Research Project of Shanxi Provincial Department of Education (18JK0401).

Availability of data and materials

The labeled dataset used to support the findings of this study is available from the corresponding author upon request.

\section{Declarations}

\section{Ethics approval and consent to participate}

Not applicable.

\section{Consent for publication}

Not applicable.

Competing interests

The authors declare that they have no competing interests.

\section{Author details}

${ }^{1}$ School of Mechanical and Electrical Engineer, Xi'an Technological University, Xi'an 710021, China. ${ }^{2}$ School of Management, Xi'anUniversity of Finance and Economics, Xi'an 710010, China.

Received: 12 June 2021 Accepted: 6 September 2021

Published online: 07 October 2021

\section{References}

1. V.M. Ciriello, The effects of box size, vertical distance, and height on lowering tasks for female industrial workers. Int. J. Ind. Ergon. 35, 857-863 (2005)

2. D. Gonen, A. Oral, M. Yosunlukaya, Computer-aided ergonomic analysis for assembly unit of an agricultural device. Hum. Factors Ergon. Manuf. Serv. Ind. 26, 615-626 (2016) 
3. Y. Jun, Z. Yu, S. Xiaofen, Rationality evaluation of ergonomic simulation in ship cabin design. Ship Eng. 41, 105-109 (2019)

4. C. Jing, W. Lei, X. Yun, Work load evaluation of lifting mawl and rwl in males. Ind. Hyg. Occup. Dis. 33, 136-169 (2007)

5. B. Alkan, D. Vera, M. Ahmad, B. Ahmad, R. Harrison, A lightweight approach for human factor assessment in virtual assembly designs: an evaluation model for postural risk and metabolic workload. Procedia CIRP 44, 26-31 (2016)

6. T. Patel, J. Sanjog, S. Karmakar, Ergonomics perspective in agricultural research: a user-centred approach using cad and digital human modeling (DHM) technologies. J. Inst. Eng. 97, 333-342 (2016)

7. T. Patel, J. Sanjog, A. Chatterjee, A. Shroff, S.S. Prusty, S. Mohapatra, S. Karmakar, Virtual ergonomics evaluation of a design concept of manual powered portable paddy thresher suitable for hilly region agriculture, in International Conference on Research Into Design (2017), pp. 503-512

8. Y. Hang, L. Gang, Y. Yang, Improving design method of loader cockpit through ergonomics simulation and analysis. J. Mech. Des. 34, 120-123 (2017)

9. Z. Jie, Yu. Fang, P. Jiazhen, Evaluation of equipment layout in virtual cockpit based on flight operation process. Comput. Integr. Manuf. Syst. 26, 655-663 (2020)

10. M. Li, Y. Li, Ergonomic simulation of elderly lower limb flexion and extension rehabilitation system based on JACK. Ind. Eng. Des. 2, 73-79 (2020)

11. P. Mojaver, S. Khalilarya, A. Chitsaz, M. Assadi, Multi-objective optimization of a power generation system based sofcusing taguchi/ahp/topsis triple method. Sustain. Energy Technol. Assess. 38, 100674 (2020)

12. M.A. Juliza, A.R.M. Faizal, T.M.S. Ratibah, A. Suryanti, I.N.S. Nadiah, Android mobile malware detection using fuzzy AHP. J. Inf. Secur. Appl. 61, 2214-2126 (2021)

13. X. Wu, F. Hu, Analysis of ecological carrying capacity using a fuzzy comprehensive evaluation method. Ecol. Indic. $113,106243(2020)$

14. Y. Fang, S. Yang, H. Qiao, L. Du, Product manufacturability evaluation method based on grey correlation algorithm extension theory. Ind. Eng. Manag. 25, 69-78 (2020)

15. X. Yang, X. Lin, L. Jiang, Research on the influence of aviation school pilot's safety performance index based on grey entropy correlation analysis. J. Civ. Aviation Flight Univ. China 32, 33-37 (2021)

16. Q. Sunchi, Q. Lei, Quantitative study on value of distinguishing coefficient in grey correlation analysis. Stat. Decis. 10 10-14 (2019)

\section{Publisher's Note}

Springer Nature remains neutral with regard to jurisdictional claims in published maps and institutional affiliations.

\section{Submit your manuscript to a SpringerOpen ${ }^{\odot}$ journal and benefit from:}

- Convenient online submission

Rigorous peer review

- Open access: articles freely available online

- High visibility within the field

- Retaining the copyright to your article

Submit your next manuscript at $\gg$ springeropen.com 